\title{
Properties of multi-walled carbon nanotube reinforced epoxy composites fabricated by using sonication and shear mixing
}

\author{
Min Ye Koo ${ }^{1,2}$, Hon Chung Shin ${ }^{1,2}$, Won-Seok Kim ${ }^{2}$ and Gyo Woo Lee ${ }^{1, \star}$ \\ 'Division of Mechanical Design Engineering, Chonbuk National University, Jeonju 561-756, Korea \\ ${ }^{2}$ International Carbon R\&D center, Korea Institute of Carbon Convergence Technology, Jeonju 561-844, Korea
}

\section{Article Info}

Received 11 August 2014

Accepted 5 September 2014

*Corresponding Author

E-mail: gwlee@jbnu.ac.kr

Tel: $+82-63-270-3997$

\section{Open Access}

DOI: http://dx.doi.org/

10.5714/CL.2014.15.4.255

This is an Open Access article distributed under the terms of the Creative Commons Attribution Non-Commercial License (http://creativecommons.org/licenses/ by-nc/3.0/) which permits unrestricted non-commercial use, distribution, and reproduction in any medium, provided the original work is properly cited.

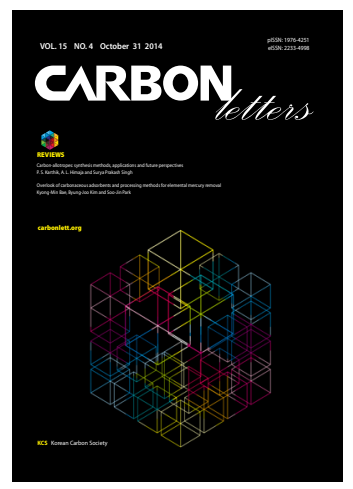

http://carbonlett.org

pISSN: 1976-4251

eISSN: 2233-4998

Copyright $\odot$ Korean Carbon Society

\begin{abstract}
Multi-walled carbon nanotube reinforced epoxy composites were fabricated using shear mixing and sonication. The mechanical, viscoelastic, thermal, and electrical properties of the fabricated specimens were measured and evaluated. From the images and the results of the measurements of tensile strengths, the specimens having $0.6 \mathrm{wt} \%$ nanotube content showed better dispersion and higher strength than those of the other specimens. The Young's moduli of the specimens increased as the nanotube filler content was increased in the matrix. As the concentrations of nanotubes filler were increased in the composite specimens, their storage and loss moduli also tended to increase. The specimen having a nanotube filler content of $0.6 \mathrm{wt} \%$ showed higher thermal conductivity than that of the other specimens. On the other hand, in the measurement of thermal expansion, specimens having 0.4 and $0.6 \mathrm{wt} \%$ filler contents showed a lower value than that of the other specimens. The electrical conductivities also increased with increasing content of nanotube filler. Based on the measured and evaluated properties of the composites, it is believed that the simple and efficient fabrication process used in this study was sufficient to obtain improved properties in the specimens.
\end{abstract}

Key words: carbon nanotube composite, sonication, shear mixing, mechanical property, thermal property

\section{Introduction}

Because they are highly adhesive to substrates and have good resistance to heat and chemicals, epoxy resins are widely used as matrices for composites. Recently, epoxy composites incorporating carbon nanotubes (CNTs) as a filler material have received a great deal of attention [1]. Due to their high strength, stiffness, aspect ratio, and thermal and electrical conductivity, CNTs are widely used as a filler material. In 2000, using an atomic force microscope (AFM) tip, Yu et al. [2] measured the outer shell strength of a multi-walled CNT and found it ranged from 11 to $63 \mathrm{GPa}$. They also determined the Young's modulus of the outermost layer to be from 270 to $950 \mathrm{GPa}$. In the same year, Xie et al. [3] reported the average tensile strength and Young's modulus of long tubes grown by chemical vapor deposition (CVD) as $\sim 3.6 \mathrm{GPa}$ and $\sim 450 \mathrm{GPa}$, respectively. The thermal conductivity and thermoelectric power of a single CNT were measured using a micro-fabricated suspended device [4]. The authors reported that the thermal conductivity was more than $3000 \mathrm{Wm}-1 \mathrm{~K}-1$ at room temperature, and the linear temperature dependence of thermoelectric power was $80 \mu \mathrm{VK}-1$.

Attractive forces between CNTs, such as van der Waal's forces, make it difficult to disperse them as filler in matrices. Well-known effective dispersion methods are divided into three categories: mechanical, physical, and chemical [1,5]. Ultrasonic dispersing and highshear mixing are examples of commonly used mechanical dispersion methods. Physical methods involve the absorption and/or wrapping of polymers or surfactants onto the surface of the nanotubes, while chemical methods involve the covalent chemical bonding of 
polymer chains to the CNTs surfaces [1]. Using the chemical method, it's possible to obtain better dispersion and resulting composite properties than with other methods, but it is a more time-consuming and expensive process than the other methods.

Many studies have been carried out with the goal of improving the mechanical properties of CNTs-reinforced epoxy composites. In 2004, Gojny et al. [6] applied a shear mixing technique to disperse double-walled CNTs in epoxy resin, with results showing poor improvement of tensile strength and stiffness. In the following year, Song and Youn [7] reported the effects of different dispersions of CNTs on the rheological, mechanical, electrical, and thermal properties of epoxy nanocomposites. In that work, the authors used field emission scanning electron microscopy (FE-SEM) and transmission electron microscopy (TEM) to characterize the dispersion. The dispersion states were altered depending on whether or not a solvent was employed. Seo and Park [8] studied the effect of the chemical treatment of multi-walled CNTs (MWCNTs) on the glass transition temperature, thermal stability, and dynamic viscoelastic behaviors of the composites. A chemical treatment was carried out using $35 \mathrm{wt} \% \mathrm{H} 3 \mathrm{PO} 4$ and $35 \mathrm{wt} \% \mathrm{KOH}$. The acid (H3PO4) treated case showed higher thermal stability and viscoelastic properties than the treated and untreated base $(\mathrm{KOH})$ samples. A mechanical dispersion method, using an ultrasonic liquid processor and a high-speed mechanical agitator, was selected to fabricate the composite specimens [9]. The case of $0.3 \mathrm{wt} \%$ CNTs-infusion showed the maximum strength enhancement. Untreated and acid-treated MWCNTs were used to fabricate epoxy composite samples using the sonication technique [10]. The results of a tensile test showed higher Young's modulus values for the composite samples prepared with acid-treated MWCNTs. Gkikas et al. [11] also showed the enhancement of thermo-mechanical and toughness properties of MWCNTs-reinforced epoxy composites. An ultrasonic mixer was used to disperse CNTs into the epoxy resin. From the results of dynamic mechanical analysis (DMA) and fracture toughness, they verified the effect of the ultrasonic dispersion of CNTs. In 2014, Lee et al. [12] fabricated MWCNT-reinforced epoxy composites by using the vacuum assisted resin transfer molding (VARTM) method. The mechanical properties, fracture surface morphologies, and thermal stabilities of the composites were evaluated with respect to the filler concentrations.

The linear coefficient of thermal expansion (CTE) was evaluated to investigate the thermal stability of hybrid composites in which carbon nanofibers and silicon dioxide particles were used as filler materials [13]. Lavorgna et al. [14] reported that both the elastic and rubbery modulus increased with the addition of silanized and silica-enriched MWCNTs filler in epoxy composites. In particular, in the rubbery region, the storage modulus of composites with silanized and silica enriched MWCNTs were about $240 \%$ and $285 \%$ higher, respectively, than that of neat epoxy. Kim et al. [15] investigated the electrical conductivity of oxidized MWCNTs epoxy composites with respect to the chemical treatment of MWCNTs. The composites containing MWCNTs oxidized by a mixture of $\mathrm{H} 2 \mathrm{O} 2$ and $\mathrm{NH} 4 \mathrm{OH}$ solution showed a higher conductivity than those having MWCNTs oxidized by nitric acid. The electrical and thermal conductivities of an epoxy composite containing $0.005-0.5 \mathrm{wt} \%$ of single-walled CNTs (SWCNTs), or MWCNTs, have also been studied [16].
The above literature review indicates that the mechanical dispersion of CNT filler is relatively less effective than chemical dispersion for enhancing the various properties of nanotubereinforced composites. However, the mechanical dispersion method has a number of advantages, including being a simple, inexpensive, and environmentally sustainable process. In the present work, MWCNT reinforced epoxy composites were fabricated using shear mixing and sonication. The concentrations of nanotube filler in the matrix were varied from 0 to $1.0 \mathrm{wt} \%$. The mechanical, viscoelastic, thermal and electrical properties of the specimens fabricated with this simple mechanical dispersion process were measured and evaluated.

\section{Experimental Details}

\subsection{Materials and composite fabrication}

YDF-161 (Bisphenol-F type) epoxy resin purchased from Kukdo Chemical Co., Ltd. (Seoul, Korea) was chosen as the matrix. Based on the material data from the manufacturer, the viscosity and density of the epoxy resin were 5-7 Pa.s and 1.17 $\mathrm{g} / \mathrm{cm}^{3}$ at $25^{\circ} \mathrm{C}$, respectively. Jeffamine D-230 manufactured by Huntsman International LLC was used as a curing agent for the epoxy resin. The viscosity and density of the hardener were about $9 \times 10^{-3} \mathrm{~Pa} \cdot \mathrm{s}$ and $0.948 \mathrm{~g} / \mathrm{cm}^{3}$ at $25^{\circ} \mathrm{C}$, respectively. Commercial grade MWCNT, M90, from Carbon Nano-material Technology Co., Ltd. (Pohang, Korea) was selected as the filler material to improve the various properties of the epoxy composite. The CNTs were used as received without any further purification. These CNTs had dimensions of 5-20 nm in diameter and about $10 \mu \mathrm{m}$ in length, with an aspect ratio of more than 500. Composite samples were fabricated using YDF-161 resin along with the hardener at a weight ratio of $3: 1$. Before mixing with the nanotube filler, the air entrapped in the epoxy resin was released using a vacuum desiccator with an air release agent (BYK-A 500; BYK-Chemie GmbH) for two hours. The CNTs were then added to the resin in appropriate amounts to reach the desired loadings, and were then dispersed in the resin using a shear mixer (PDM-300 Paste mixer; Dae Wha Tech. Co., Ltd., Yongin, Korea) and an ultrasonic bath sonicator (WUC$\mathrm{A} 03 \mathrm{H}, 100 \mathrm{~W}$ peak out, $40 \mathrm{kHz}$ frequency; Daihan Scientific Co., Seoul, Korea). After mixing with the filler, a curing agent was added and mixed with the epoxy resin using a paste mixer. When the mixing of epoxy resin with the filler and hardener was completed, the resin mixture was poured into silicone molds and cured at $400 \mathrm{kPa}$ pressure and room temperature for one day. This was followed by post curing in an oven at $80^{\circ} \mathrm{C}$ for $6 \mathrm{~h}$. The detailed fabrication process is shown in Fig. 1.

Specimens having different filler loadings were prepared from baseline (that is, neat epoxy) to $1.0 \mathrm{wt} \%$ filler content specimens with respect to the total weight of the resin and the hardener. $115 \mathrm{~mm}$-long and more than $4 \mathrm{~mm}$-thick dog-bone shaped specimens fabricated following the standard test method (ASTM D638-10) were used in the investigation of tensile strength and stiffness. Rectangular-shaped $35 \mathrm{~mm}(\mathrm{~L}) \times 10 \mathrm{~mm}$ (W) specimens with $1.5 \mathrm{~mm}$ thickness were used in dynamicmechanical analysis (DMA) to measure the damping property of the specimens. Other rectangular specimens $(45 \mathrm{~mm}[\mathrm{~L}] \times 10$ 


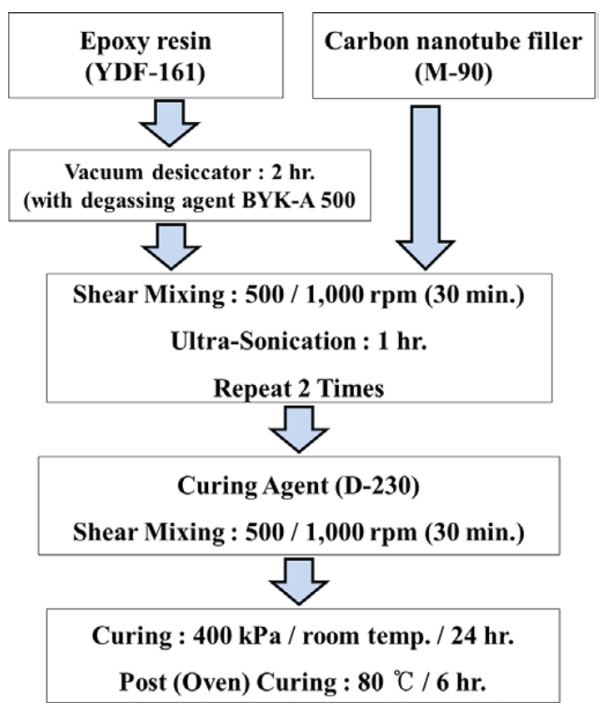

Fig. 1. A schematic diagram of the fabrication process for carbonnanotube-reinforced epoxy composite using ultra-sonication and shear mixing.

$\mathrm{mm}[\mathrm{W}]$ ) of $3 \mathrm{~mm}$ thickness were fabricated and used to determine the CTE. The thermal and electrical conductivities were measured using $25 \mathrm{~mm}$-diameter circular specimens of 2 and 3 $\mathrm{mm}$ thickness.

\subsection{Measurements}

In this study, a FE-SEM (S-4700; Hitachi Ltd., in Korea Basic Science Institute [KBSI] Jeonju Center, Jeonju, Korea) was used to qualitatively assess the dispersion of the nanotube filler in a matrix, using high and low magnified images. A tensile test, using a universal testing machine (RB 301 Unitech T; R\&B Inc., Daejeon, Korea), was also used to quantitatively assess the filler dispersion from the values and deviations of the tensile strengths and stiffnesses. It is well known that mechanical properties such as the tensile strength of well-dispersed specimens usually have relatively small deviation. DMA (Q800; TA Instruments) were performed to determine the effect of the nanotube filler on the viscoelastic property of the composite with temperature. Both the storage and loss modulus were measured. The temperatures were varied from room temperature to $120^{\circ} \mathrm{C}$. Tests were performed at a frequency of $1 \mathrm{~Hz}$ under the condition of a single cantilever at $3^{\circ} \mathrm{C} / \mathrm{min}$ temperature increments.

The coefficients of thermal expansion of the specimens were calculated from measured thermal strain differences divided by temperature differences. The thermal strains were measured using strain gages (CEA-13-240UZ-120; Micro-measurements) and a strain indicator (P3; Micro-measurements) using a half bridge connection. Also, the temperatures of the specimens were measured using T-type thermocouples (TG-T-36-500; Omega Engineering, Inc.) and an A/D converter (34970A; Agilent Technologies). Another thermal property, the thermal conductivity, was measured using a thermal conductivity measurement system (ThermoCon M100; Hantech Co., Ltd., Gunpo, Korea) in accordance with the ASTM D5470 standard. The threshold and improvement of the electrical property of the nanotube-added


Fig. 2. Scanning electron microscopy images of the fracture surfaces of specimens for carbon nanotube (CNT) filler concentrations of $0.6 \mathrm{wt} \%$ ([a] and $[c]$, images on the left hand side) and $1.0 \mathrm{wt} \%$ ([b] and [d], right hand side).

composite specimens were investigated from the measurement of electrical conductivity (FPP-RS8[1G]; Dasol Engineering Co., Ltd., Cheongju, Korea).

\section{Results and Discussion}

Excellent dispersion of the nanotube filler in the matrix is essential for improving several properties of the composites. To assess the filler dispersion in the epoxy matrix, the fracture surfaces of specimens cooled by liquid nitrogen were magnified, and are shown in Fig. 2. Fig. 2a and c show 500 and 50 000 times magnified fracture surface images, respectively, of the specimen containing $0.6 \mathrm{wt} \%$ CNT filler. The images on the right hand side (Fig. $2 b$ and d) show the composite specimen having $1.0 \mathrm{wt} \%$ nanotube filler. It is difficult to determine the dispersion status in the two lower, highly magnified, images.

However, it is clear that the case of $0.6 \mathrm{wt} \%$ nanotube filler in Fig. 2a shows better dispersion than the case of $1.0 \mathrm{wt} \%$ filler content shown in the Fig. 2c. Fig. 2c shows more and larger agglomerates of CNTs than those in Fig. 2a. Although the results are restricted to the fabrication process used in this study, from this qualitative result we believe that the specimen with $1.0 \mathrm{wt} \%$ nanotubes has an excessive amount of nanotube filler.

Figs. 3 and 4 show the tensile strength and stiffness of the composite specimens, respectively. More than 5 specimens were tested in each case, and the data were averaged. Data labels in both figures are the strengths and moduli. The values in parentheses indicate a percentile increment with respect to those of baseline specimens. In the case of specimens with $0.6 \mathrm{wt} \%$ CNTs, approximately $14 \%$ improvement in tensile strength is obtained with respect to the baseline, showing the highest tensile strength tested. The case of the $0.8 \mathrm{wt} \% \mathrm{CNTs}$ specimens showed a lower strength than the case of the $0.6 \mathrm{wt} \%$ CNTs specimens, but was still higher than the baseline. As shown in Fig. 3, there are only relatively small deviations from the significant increments of strength, and it is believed that the fabrication process of this study is sufficiently reliable. In contrast to 


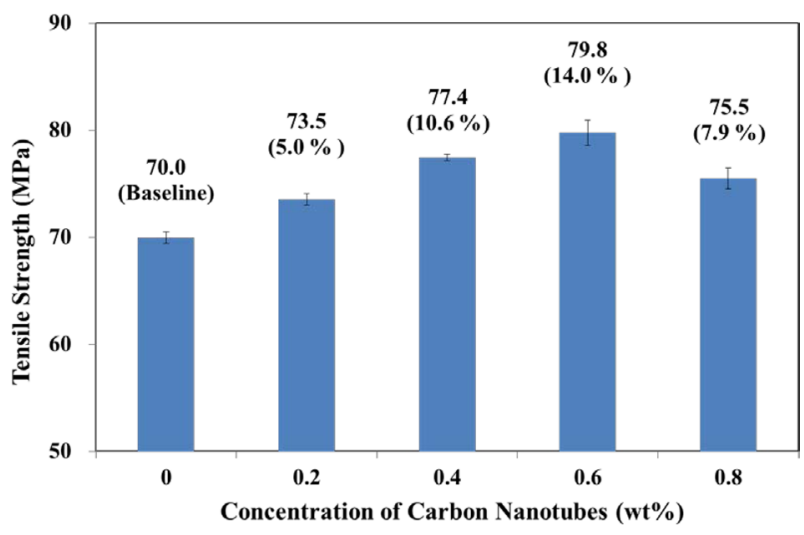

Fig. 3. Averaged tensile strengths and standard deviations with respect to the concentrations of carbon nanotube filler.



Fig. 4. Averaged Young's moduli and standard deviations with respect to the concentrations of carbon nanotube filler.

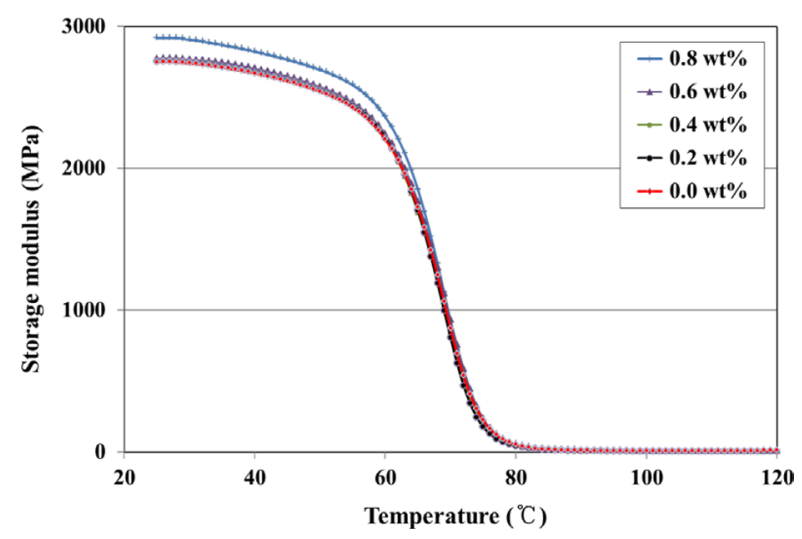

Fig. 5. Storage moduli of several specimens containing carbon nanotube filler as a result of dynamic mechanical analyses with respect to the temperature increase.

the tensile strengths shown in Fig. 3, the Young's moduli shown in Fig. 4 demonstrate a tendency to increase from the baseline to the $0.8 \mathrm{wt} \%$ CNTs samples. The measured Young's modulus of the $0.8 \mathrm{wt} \%$ CNTs specimens is $3.11 \mathrm{GPa}$, which is $13.1 \%$ higher than that of the baseline samples.

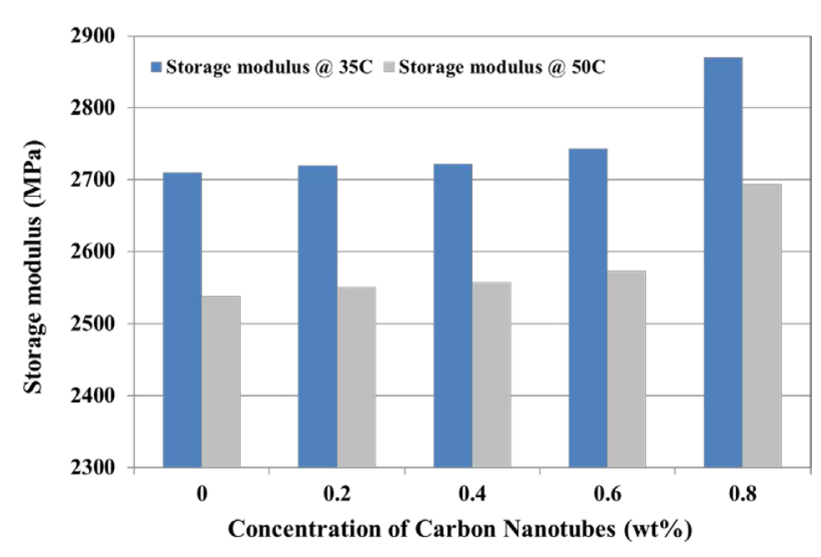

Fig. 6. Storage moduli of several specimens containing carbon nanotube filler as a result of dynamic mechanical analyses at temperatures of $35^{\circ} \mathrm{C}$ and $50^{\circ} \mathrm{C}$.

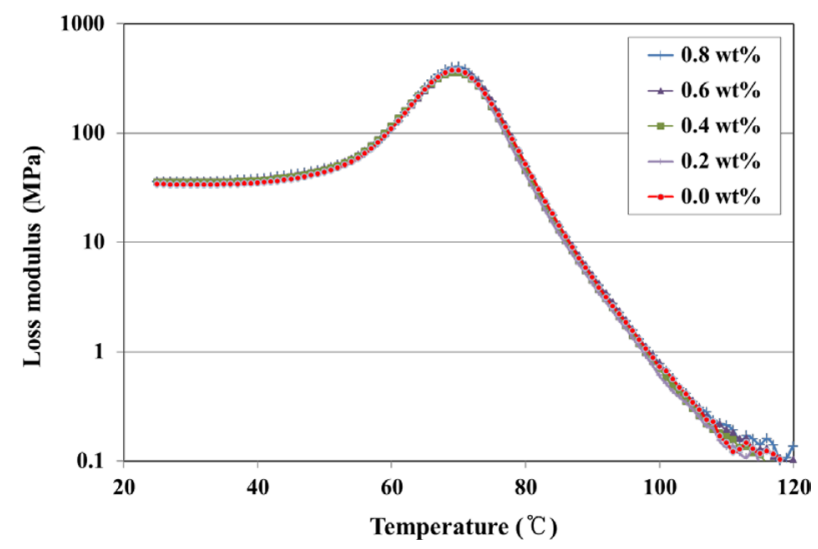

Fig. 7. Loss moduli of several specimens containing carbon nanotube filler as a result of dynamic mechanical analyses with respect to the temperature increase.

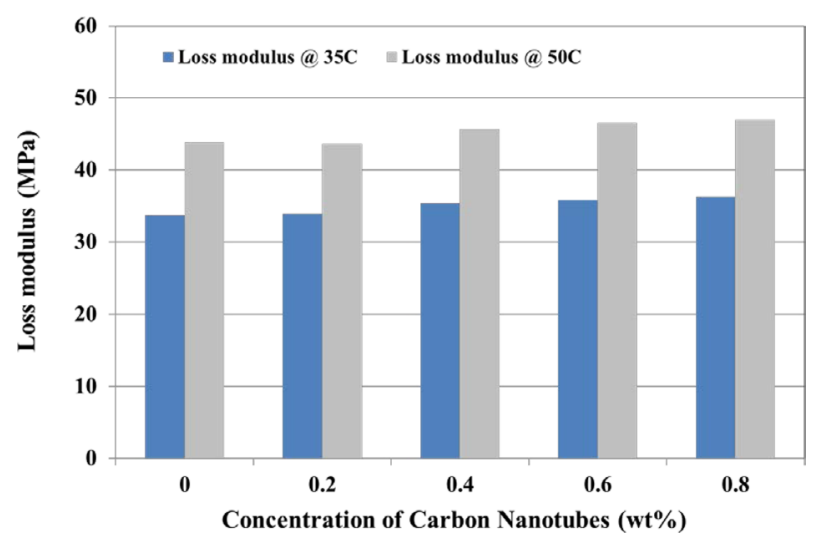

Fig. 8. Loss moduli of several specimens containing carbon nanotube filler as a result of dynamic mechanical analyses at temperatures of $35^{\circ} \mathrm{C}$ and $50^{\circ} \mathrm{C}$.

Figs. 5-8 show the results of the dynamic mechanical analyses. In the glassy plateau region shown in Fig. 5, it can clearly be seen that the $0.8 \mathrm{wt} \%$ CNTs sample shows the highest storage modulus, but the tendency among the other cases is not clear. 


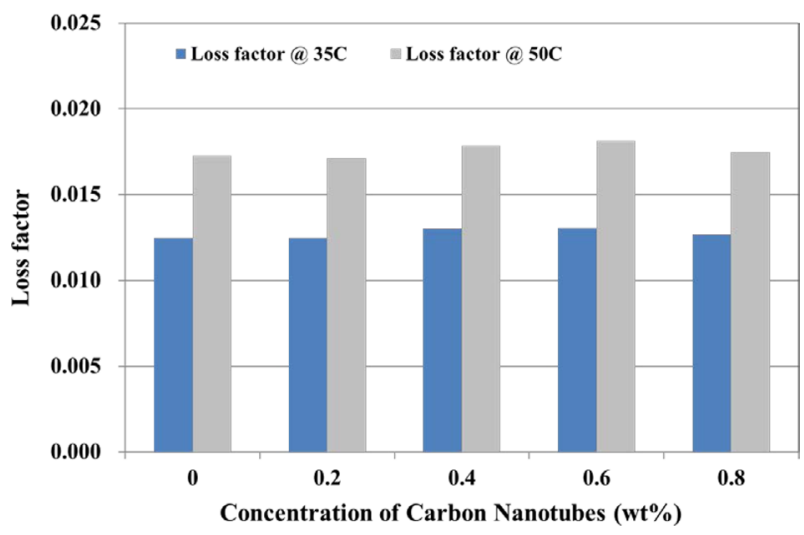

Fig. 9. Loss factors of several specimens containing carbon nanotube filler as a result of dynamic mechanical analyses at temperatures of $35^{\circ} \mathrm{C}$ and $50^{\circ} \mathrm{C}$.

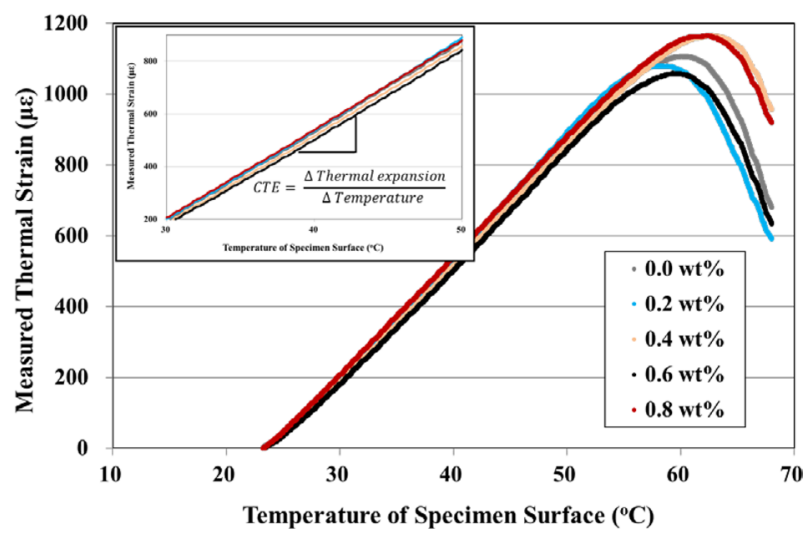

Fig. 10. Measured thermal strains of several specimens containing carbon nanotube filler with temperature of specimen surface. CTE: coefficient of thermal expansion.

Therefore, the storage moduli of these cases at temperatures of $35^{\circ} \mathrm{C}$ and $50^{\circ} \mathrm{C}$ are plotted in Fig. 6 .

In this experiment, as the concentrations of CNTs filler in the composite specimens are increased, their storage moduli also tend to increase. Similar to Figs. 5 and 6, Figs. 7 and 8 show the loss moduli with temperature variation and the detailed moduli at temperatures of $35^{\circ} \mathrm{C}$ and $50^{\circ} \mathrm{C}$, respectively. Although no tendency of loss modulus with respect to the filler concentration can be seen in Fig. 7, slight increments of the moduli with filler concentrations at the two temperatures are clearly seen in Fig. 8. The ratio of loss to storage moduli is called the loss factor or tangent delta and is an indicator of the viscoelasticity of a specimen. The loss factors of these specimens at temperatures of $35^{\circ} \mathrm{C}$ and $50^{\circ} \mathrm{C}$ are plotted in Fig. 9, but only the small increments are seen from the baseline to the $0.6 \mathrm{wt} \% \mathrm{CNT}$ content specimens. These small differences of loss factors with respect to the CNT filler concentrations might be caused by the excessively small increments in the measurement of loss moduli from the baseline to the $0.6 \mathrm{wt} \%$ CNTs specimens, as seen in Fig. 8.

Thermal strains with temperature increases were measured and are plotted in Fig. 10. The temperature increment was

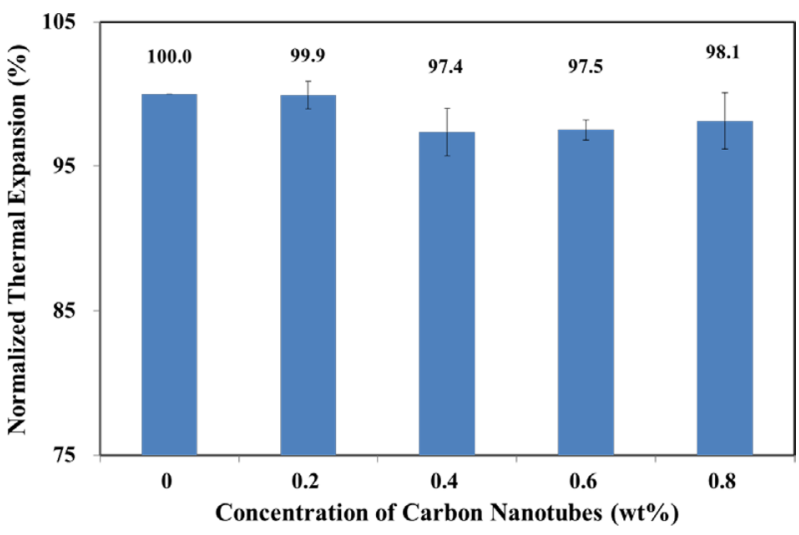

Fig. 11. Normalized coefficients of thermal expansion of specimens with concentrations of carbon nanotubes.

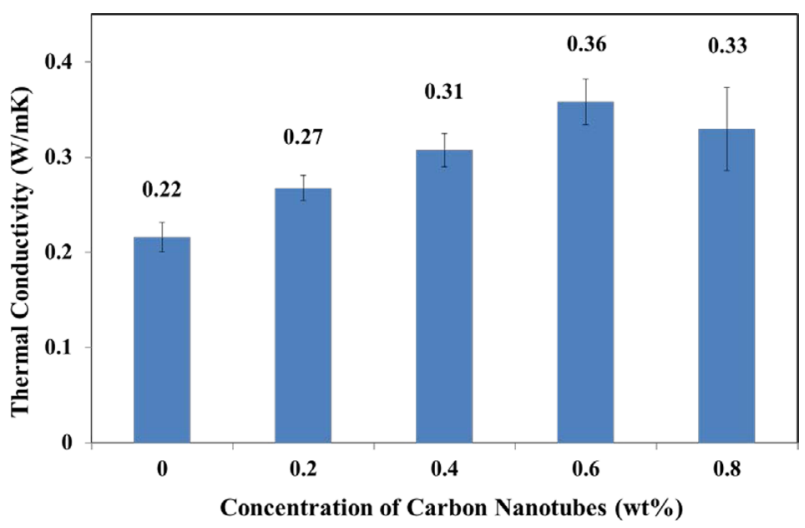

Fig. 12. Thermal conductivities of several specimens with concentrations of carbon nanotubes.

$1^{\circ} \mathrm{C}$ per $3 \mathrm{~min}$ from room temperature to $67^{\circ} \mathrm{C}$. The temperature of the specimens' surface and the thermal strain were measured and stored at one second increments using a data logger and computer. From these raw data, linear sections were selected from $30^{\circ} \mathrm{C}$ to $50^{\circ} \mathrm{C}$ to calculate the coefficients of thermal expansion, as seen in the small figure in Fig. 10. Three groups of thermal strain measurements were performed and the CTEs were calculated. The CTEs were then averaged and normalized with respect to those of the baseline, as shown in Fig. 11. The specimens containing 0.4 and $0.6 \mathrm{wt} \%$ CNTs show lower thermal expansions than those of the other specimens. A thermal stability enhancement of only $2.6 \%$ was obtained. While the CNT filler may be helpful in strengthening the cross-link of the epoxy composite, the improved heat transfer of the specimen produced by the filler is detrimental to the thermal stability of the composite specimen. The competition between these positive and negative contributions to thermal stability might cause the small increase in thermal stability.

Thermal conductivity, another factor related to the thermal property of the composite, was measured and plotted, as shown in Fig. 12. The averaged thermal conductivities of the specimens with $0.2,0.4,0.6$, and $0.8 \mathrm{wt} \%$ of CNTs filler were measured to be around $0.27,0.31,0.36$, and $0.33 \mathrm{Wm}-1 \mathrm{~K}-1$, respectively, 


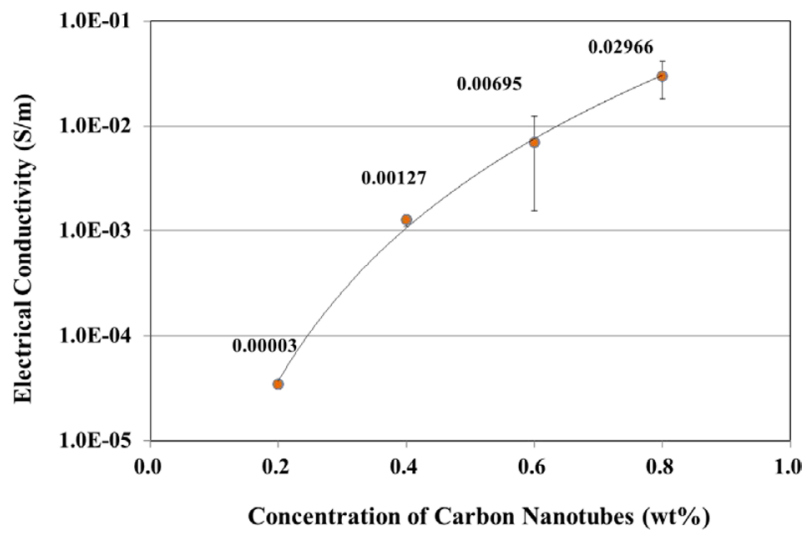

Fig. 13. Electrical conductivities of several specimens with concentrations of carbon nanotubes.

while the conductivity of the baseline was measured to be 0.22 $\mathrm{Wm}-1 \mathrm{~K}-1$. Similar to the results for tensile strength, the $0.6 \mathrm{wt} \%$ CNTs specimens show higher thermal conductivity than that of the other specimens. An improvement of thermal conductivity of about $64 \%$ over that of the baseline was achieved with a nanotube filler of only $0.6 \mathrm{wt} \%$.

In contrast to thermal conductivity, the electrical conductivity increased consistently with the concentration of the nanotube filler, as shown in Fig. 13. The averaged electrical conductivities of the specimens with $0.2,0.4,0.6$, and $0.8 \mathrm{wt} \%$ of CNTs filler were measured to be around $0.00003,0.00127,0.00695$, and $0.02966 \mathrm{Sm}-1$, respectively. The threshold value of the nanotube filler content for the electrical conductivity appears to be lower than $0.2 \mathrm{wt} \%$.

\section{Conclusions}

In this experiment, multi-walled-carbon-nanotube reinforced epoxy composites were fabricated using shear mixing and sonication. The concentrations of the nanotube filler in the matrix were varied from 0 to $1.0 \mathrm{wt} \%$. The mechanical, viscoelastic, thermal, and electrical properties of the fabricated specimens were measured and evaluated. To confirm the nanotubes were well dispersed in the epoxy matrix, samples were investigated with electron microscope images and tensile tests. On the basis of the images and the measured tensile strengths, the specimens having a nanotube content of 0.6 $\mathrm{wt} \%$ showed better dispersion and higher strength than those of the other specimens. The Young's moduli of the specimens were increased as the content of nanotube filler in the matrix was increased. As the concentrations of the nanotubes filler in the composite specimens were increased, the storage and loss moduli also tended to increase. A higher thermal conductivity than that of the other specimens was measured for the specimen having $0.6 \mathrm{wt} \%$ nanotube filler content. In contrast, lower values of thermal expansion were measured for those having 0.4 and $0.6 \mathrm{wt} \%$ filler contents, as compared with other samples. The electrical conductivities also increased with the increasing content of nanotube filler. Based on the measured and evaluated properties of the composites, it is believed that the simple and efficient fabrication process for nanotube reinforced epoxy specimens proposed in this study was sufficient to obtain specimens with improved properties.

\section{Acknowledgements}

This research was supported by the Basic Science Research Program through the National Research Foundation of Korea (NRF) funded by the Ministry of Education, Science and Technology (Grant No. NRF-2011-0009109) and a grant from the Fundamental R\&D Program for Technology of "World Premier Materials" funded by the Ministry of Trade, Industry \& Energy (MOTIE), Republic of Korea.

\section{References}

[1] Jin FL, Park SJ. Recent advances in carbon-nanotube-based epoxy composites. Carbon Lett, 14, 1 (2013). http://dx.doi.org/10.5714/ CL.2012.14.1.001.

[2] Yu MF, Lourie O, Dyer MJ, Moloni K, Kelly TF, Ruoff RS. Strength and breaking mechanism of multiwalled carbon nanotubes under tensile load. Science, 287, 637 (2000). http://dx.doi. org/10.1126/science.287.5453.637.

[3] Xie S, Li W, Pan Z, Chang B, Sun L. Mechanical and physical properties on carbon nanotube. J Phys Chem Solids, 61, 1153 (2000). http://dx.doi.org/10.1016/S0022-3697(99)00376-5.

[4] Kim P, Shi L, Majumdar A, McEuen PL. Thermal transport measurements of individual multiwalled nanotubes. Phys Rev Lett, 87, 215502 (2001). http://dx.doi.org/10.1103/PhysRevLett.87.215502.

[5] Hilding J, Grulke EA, George Zhang Z, Lockwood F. Dispersion of carbon nanotubes in liquids. J Dispersion Sci Technol, 24, 1 (2003). http://dx.doi.org/10.1081/DIS-120017941.

[6] Gojny FH, Wichmann MHG, Köpke U, Fiedler B, Schulte K. Carbon nanotube-reinforced epoxy-composites: enhanced stiffness and fracture toughness at low nanotube content. Compos Sci Technol, 64, 2363 (2004). http://dx.doi.org/10.1016/j.compscitech. 2004.04.002.

[7] Song YS, Youn JR. Influence of dispersion states of carbon nanotubes on physical properties of epoxy nanocomposites. Carbon, 43, 1378 (2005). http://dx.doi.org/10.1016/j.carbon.2005.01.007.

[8] Seo MK, Park SJ. Studies on thermal and dynamic viscoelastic behaviors of multiwalled carbon nanotubes-reinforced epoxy matrix composites. Korean Chem Eng Res, 43, 401 (2005).

[9] Zhou Y, Pervin F, Lewis L, Jeelani S. Experimental study on the thermal and mechanical properties of multi-walled carbon nanotube-reinforced epoxy. Mater Sci Eng A, 452-453, 657 (2007). http://dx.doi.org/10.1016/j.msea.2006.11.066.

[10] Montazeri A, Javadpour J, Khavandi A, Tcharkhtchi A, Mohajeri A. Mechanical properties of multi-walled carbon nanotube/ epoxy composites. Mater Design, 31, 4202 (2010). http://dx.doi. org/10.1016/j.matdes.2010.04.018.

[11] Gkikas G, Barkoula NM, Paipetis AS. Effect of dispersion conditions on the thermo-mechanical and toughness properties of multi walled carbon nanotubes-reinforced epoxy. Composites B, 43, 2697 (2012). http://dx.doi.org/10.1016/j.compositesb.2012.01.070.

[12] Lee SE, Cho SH, Lee YS. Mechanical and thermal properties of MWCNT-reinforced epoxy nanocomposites by vacuum assisted 
resin transfer molding. Carbon Lett, 15, 32 (2014). http://dx.doi. org/10.5714/CL.2014.15.1.032.

[13] Jang JS, Varischetti J, Lee GW, Suhr J. Experimental and analytical investigation of mechanical damping and CTE of both $\mathrm{SiO}_{2}$ particle and carbon nanofiber reinforced hybrid epoxy composites. Composites A, 42, 98 (2011). http://dx.doi.org/10.1016/j.compositesa.2010.10.008.

[14] Lavorgna M, Romeo V, Martone A, Zarrelli M, Giordano M, Buonocore GG, Qu MZ, Fei GX, Xia HS. Silanization and silica enrichment of multiwalled carbon nanotubes: synergistic effects on the thermal-mechanical properties of epoxy nanocomposites.
Eur Polym J, 49, 428 (2013). http://dx.doi.org/10.1016/j.eurpolymj.2012.10.003.

[15] Kim YJ, Shin TS, Choi HD, Kwon JH, Chung YC, Yoon HG. Electrical conductivity of chemically modified multiwalled carbon nanotube/epoxy composites. Carbon, 43, 23 (2005). http://dx.doi. $\operatorname{org} / 10.1016 /$ j.carbon.2004.08.015.

[16] Moisala A, Li Q, Kinloch IA, Windle AH. Thermal and electrical conductivity of single- and multi-walled carbon nanotube-epoxy composites. Compos Sci Technol, 66, 1285 (2006). http://dx.doi. org/10.1016/j.compscitech.2005.10.016. 